\title{
Reference standards for quantitative trace analysis of PCB's by GC. Technical PCB formulations for the calibration of ECD and MSD responses
}

\author{
Citation for published version (APA): \\ Krupcik, J., Kocan, A., Petrik, J., Leclercq, P. A., \& Ballschmiter, K. (1993). Reference standards for quantitative \\ trace analysis of PCB's by GC. Technical PCB formulations for the calibration of ECD and MSD responses. \\ Chromatographia, 35(7-8), 410-418. https://doi.org/10.1007/BF02278595
}

DOI:

10.1007/BF02278595

Document status and date:

Published: 01/01/1993

\section{Document Version:}

Publisher's PDF, also known as Version of Record (includes final page, issue and volume numbers)

\section{Please check the document version of this publication:}

- A submitted manuscript is the version of the article upon submission and before peer-review. There can be important differences between the submitted version and the official published version of record. People interested in the research are advised to contact the author for the final version of the publication, or visit the DOI to the publisher's website.

- The final author version and the galley proof are versions of the publication after peer review.

- The final published version features the final layout of the paper including the volume, issue and page numbers.

Link to publication

\footnotetext{
General rights

- You may freely distribute the URL identifying the publication in the public portal. follow below link for the End User Agreement:

www.tue.nl/taverne

\section{Take down policy}

If you believe that this document breaches copyright please contact us at:

openaccess@tue.nl

providing details and we will investigate your claim.
}

Copyright and moral rights for the publications made accessible in the public portal are retained by the authors and/or other copyright owners and it is a condition of accessing publications that users recognise and abide by the legal requirements associated with these rights.

- Users may download and print one copy of any publication from the public portal for the purpose of private study or research.

- You may not further distribute the material or use it for any profit-making activity or commercial gain

If the publication is distributed under the terms of Article $25 \mathrm{fa}$ of the Dutch Copyright Act, indicated by the "Taverne" license above, please 


\title{
Reference Standards for Quantitative Trace Analysis of PCB's by GC. Technical PCB Formulations for the Calibration of ECD and MSD Responses
}

\author{
J. Krupcík ${ }^{1 *} /$ A. Kocan ${ }^{2} /$ J. Petrík ${ }^{2}$ / P. A. Leclercq ${ }^{3} /$ K. Ballschmiter ${ }^{4}$ \\ ${ }^{1}$ Slovak Technical University, Faculty of Chemistry, Department of Analytical Chemistry, Radlinského 9, \\ 81237 Bratislava, Slovakia \\ ${ }^{2}$ Institute of Preventive Medicine, Limbová 14, 83301 Bratislava, Slovakia \\ ${ }^{3}$ Eindhoven University of Technology, Department of Chemical Engineering, Laboratory of Instrumental Analysis, \\ P.O. Box 513, 5600 MB Eindhoven, The Netherlands \\ ${ }^{4}$ University of Ulm, Department of Analytical and Environmental Chemistry, $7900 \mathrm{Ulm}$, Germany
}

\section{Key Words}

Capillary gas chromatography

Polychlorinated biphenyls (PCBs)

Quantitative analysis

Detector response factors (FID, ECD, MS)

\section{Summary}

The composition of any technical PCB formulation can be determined directly by analyzing the PCB sample by gas chromatography with a flame ionization detector (GC-FID), provided the relative molecular masses of the components are known. The responses of electron capture and selected-ion monitoring, mass-spectra detectors can then be calibrated for individual PCB congeners by correlation of the chromatographic patterns with those of concentrated PCB samples obtained by GC-FID. This procedure, which uses a given technical PCB formulation as a secondary reference standard mixture, is to be preferred over existing calibration methods, when results with $\pm 10 \%$ errors are acceptable because commercial PCB formulations cover the whole range of chlorination products.

\section{Introduction}

Capillary gas chromatography (GC) with an electron capture detector (ECD), or a mass spectrometric detector in the selected-ion monitoring mode (MSSIM), provides the best specificity and selectivity for trace analysis of polychlorinated biphenyls (PCBs) in various environmental and biological samples [1].

It is known that the ECD response to PCBs is dependent both on the number of chlorine atoms present as well as on the chlorine substitution pattern on the biphenyl skeleton $[1,3,4]$. Owing to very poor reproducibility, published responses and response factors cannot simply be applied for calibration under various instrumental and working conditions. Therefore, the ECD response to PCBs must be calibrated prior to GC-ECD trace analysis. As there are 209 PCB congeners, it is a time-consuming and expensive task to carry out such calibrations using the full set of congeners on a daily laboratory basis. For this reason, quantitation requires secondary standards or certified PCB standards available to the many analysts presently involved in PCB trace analysis.

An acceptable solution for calibrating responses for 203 of the 209 PCBs was published by Cooper et al. [2], who used a mixture containing 31 reference $P C B$ congeners, each of which representing a group of congeners with similar response factors. A similar concept was proposed by the Canadian Marine Research Institute where 51 PCB congeners are used [5]. The specificity of GC-MS-SIM analysis of PCBs is excellent with regard to the number of halogen atoms and the relative molecular mass. However, there are problems of distinguishing isomers because of lack of specific masses, corresponding to the isomeric structure in the fragmentation pattern of the spectra. For PCBs the most important electron-ionization, mass-spectra feature is the molecular ion cluster $\left(\mathrm{M}^{+}\right)$. The ions selected for MS-SIM, PCB monitoring represent the most abundant peak in each of the $\mathrm{M}^{+}$ion clusters. The application of the GC-MS-SIM method for selective trace determinations of $\mathrm{PCB}$ congeners and total $\mathrm{PCB}$ content, requires calibration of MS-SIM responses. A mixture of nine reference PCB congeners was used for the calibration of MS-SIM mean responses of isomeric groups, using a computerized capillary GC-MS system [6]. Individual response factors within an isomer group, however, varied by a factor of 1.16-2.15 [1] or 1.3-4.6 [6], which is almost unacceptable for trace GC-MS-SIM analysis. 
In a previous paper [7] we described a new procedure to derive, from any technical PCB formulation, a secondary reference standard mixture suitable for calibration. The aim of this paper is to report experience of those secondary reference standards for calibration of ECD, MS-TIC and MS-SIM responses.

\section{Experimental}

\section{Gas Chromatography}

A HP 5890A gas chromatograph, equipped with FID and ECD detectors was used (Hewlett Packard, Waldbronn, FRG). GC-FID and GC-ECD chromatograms were recorded and evaluated by a HP 3393 integrators. Separations were performed on a $50 \mathrm{~m} \times 0.2 \mathrm{~mm}$ i.d. fused-silica capillary-column, coated with a crosslinked polydimethylsiloxane elastomer (PONA column, Hewlett Packard). The column temperature was programmed from $180^{\circ} \mathrm{C}$ at a rate of $1^{\circ} \mathrm{C} \mathrm{min}-1$. The detectors were maintained above the final column temperature: FID at $300^{\circ} \mathrm{C}, \mathrm{ECD}$ at $320^{\circ} \mathrm{C}$, respectively. Helium, at a linear velocity of $40 \mathrm{~cm} \mathrm{~s}^{-1}$ at $180^{\circ} \mathrm{C}$, was used as carrier gas, and nitrogen, at $100 \mathrm{ml} \mathrm{min}^{-1}$, as make-up gas for the ECD.

\section{GC-MS}

A HP 5890A gas chromatograph combined with a HP 5970B MSD was used for total-ion-current (GC-MSTIC) and selected-ion monitoring (GC-MS-SIM) (all isntruments Hewlett Packard). The GC working conditions were the same as those given above for GC-FID and GC-ECD.

The GC-MS interface was kept at $250^{\circ} \mathrm{C}$; the electron energy was $70 \mathrm{eV}$, and the electron multiplier was operated at $2200 \mathrm{~V}$. With GC-MS-SIM, the following ions $(\mathrm{m} / \mathrm{z})$ were monitored: $188.00,222.00,255.95$, $291.90,325.90,359.85,393.85$ and 429.75 dalton, with a dwell time of $45 \mathrm{~ms}$ each. With GC-MS-TIC, mass spectra were scanned from $\mathrm{m} / \mathrm{z} 50$ to $\mathrm{m} / \mathrm{z} 480$ every second.

\section{Samples and Sample Introduction}

Samples of technical PCB formulations, both for GC as well as for GC-MS, were diluted in $n$-hexane $(5 \mu \mathrm{g}$ $\mathrm{ml}^{-1}$ ) and injected using an inlet splitter operated at $280^{\circ} \mathrm{C}$, with a $1: 100$ ratio. Aroclor 1242 , Aroclor 1260 , Delor 103 and Delor 106 were from Chemko Strážske (Slovakia).

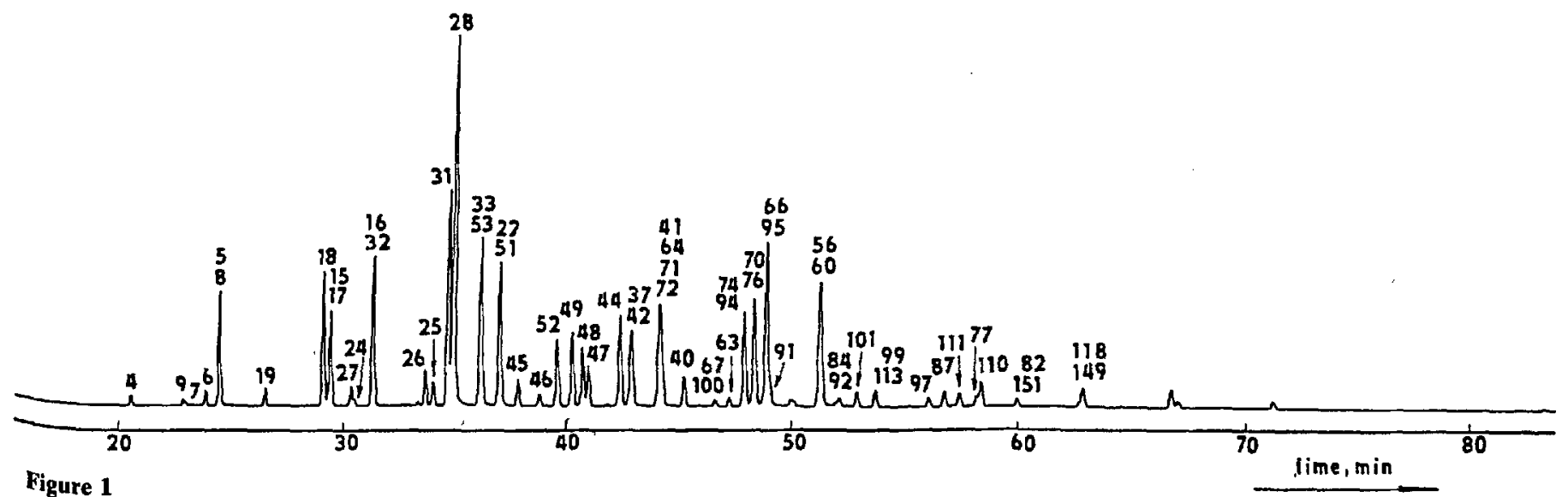

Figure 1

Separation of 50ng Aroclor 1242 by GC-ECD. Conditions given under Experimental.

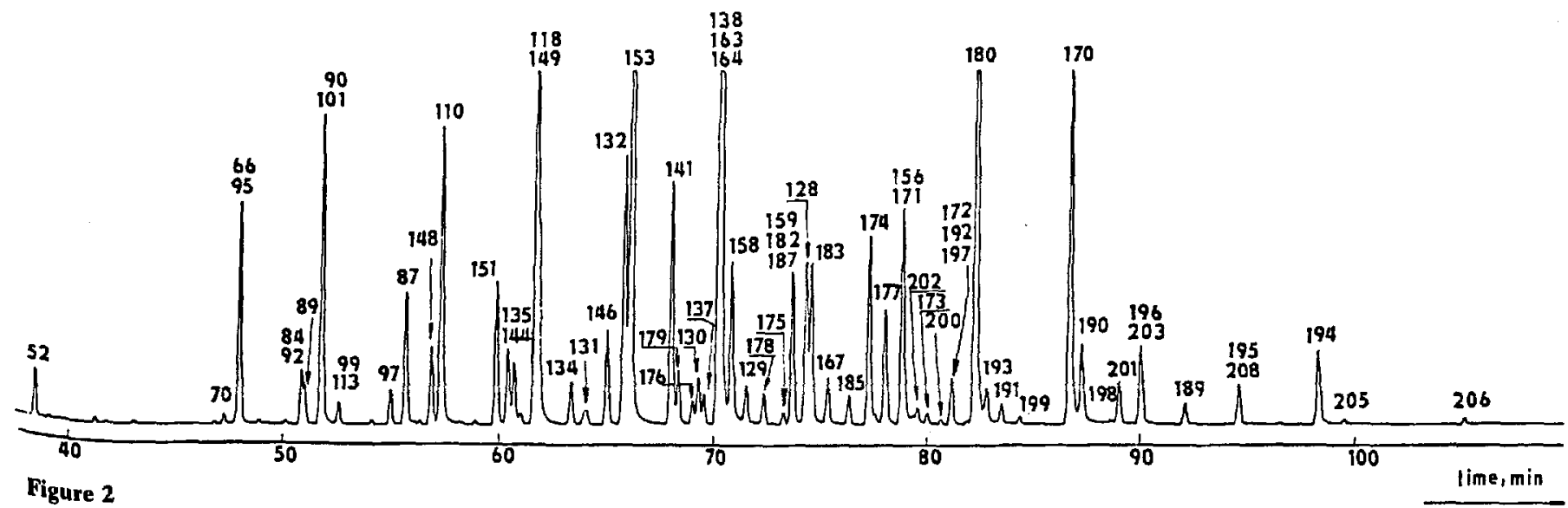

Separation of 50ng Aroclor 1260 by GC-ECD. Conditions given under Experimental. 


\section{Results and Discussion}

In a previous paper [7] we showed that any technical PCB formulation analyzed by GC-FID can be used as a secondary reference mixture for calibrating EC and MS detection, used frequently in PCB trace analysis. One of the requirements for the exploitation of such procedures is to analyze technical $\mathrm{PCB}$ formulations by $\mathrm{GC}$ with all appropriate detection techniques under

Table I Mass responses (R), mass response factors (RF) and relative mass response factors (RRF) of major ${ }^{\mathrm{a}}$ congeners found for ECD by GC of Aroclor 1242.

\begin{tabular}{|c|c|c|c|c|c|}
\hline $\mathrm{SN}^{\mathrm{b}}$ & $\underset{10^{6}}{\stackrel{\mathrm{R}}{\mathrm{cnts} \mathrm{pg}} \mathrm{pg}^{-1}}$ & $\begin{array}{c}\text { RF } \\
\text { ng } 10^{-7} \mathrm{cnts}^{-1}\end{array}$ & RRF & $R_{R F}{ }^{c}$ & $R R F^{d}$ \\
\hline 4 & 0.1799 & 55.57 & 2.73 & 14.01 & 4.44 \\
\hline 6 & 0.9993 & 10.01 & 1.57 & 1.38 & 3.25 \\
\hline 5 & & & & 4.40 & 5.49 \\
\hline 8 & 0.6531 & 15.31 & 2.41 & 2.54 & 1.98 \\
\hline 19 & 0.9369 & 10.67 & 1.68 & 1.73 & 2.12 \\
\hline 18 & 0.6485 & 15.42 & 2.42 & 1.67 & 1.05 \\
\hline 15 & & & & 4.90 & 2.88 \\
\hline 17 & 0.7371 & 13.57 & 2.13 & 1.27 & 1.04 \\
\hline 27 & 1.837 & 5.444 & 0.855 & 1.06 & 1.33 \\
\hline 16 & & & 137 & 1.17 & 1.16 \\
\hline 32 & 1.146 & 8.724 & 1.37 & 1.88 & 1.14 \\
\hline 26 & 1.625 & 6.153 & 0.967 & 0.869 & 0.997 \\
\hline 25 & 2.289 & 4.369 & 0.686 & 1.05 & 2.05 \\
\hline 31 & 1.144 & 8.745 & 1.37 & 0.932 & 1.05 \\
\hline 28 & 1.434 & 6.975 & 1.10 & 0.613 & 0.803 \\
\hline 33 & & & & 1.17 & 1.07 \\
\hline 53 & 1.217 & 8.214 & 1.29 & 1.43 & 1.16 \\
\hline 22 & 1890 & & 0.864 & 0.479 & 0.325 \\
\hline 51 & 1.820 & 3.496 & 0.804 & 0.873 & 1.63 \\
\hline 45 & 1.731 & 5.778 & 0.908 & 0.970 & 1.01 \\
\hline 46 & 1.752 & 5.708 & 0.897 & 1.12 & - \\
\hline 52 & & & & 1.25 & 0.625 \\
\hline 69 & 1.146 & 8.728 & 1.37 & 0.653 & 0.772 \\
\hline 49 & 1.414 & 7.075 & 1.11 & 0.808 & 0.744 \\
\hline 48 & 1.857 & 5.384 & 0.846 & 0.942 & 0.922 \\
\hline 47 & 1.665 & 6.004 & 0.943 & 0.618 & 0.619 \\
\hline $44^{*}$ & 1.571 & 6.364 & 1.00 & 1.00 & 1.00 \\
\hline 37 & & & & 0.903 & 1.68 \\
\hline 42 & 1.004 & 9.955 & 1.56 & 0.662 & 0.709 \\
\hline 41 & & & & 0.958 & 0.850 \\
\hline 64 & & & & 0.863 & 0.603 \\
\hline 71 & 2.095 & 4.773 & 0.750 & 1.12 & 1.13 \\
\hline 72 & & & & 0.950 & 0.500 \\
\hline 40 & 2.328 & 4.295 & 0.675 & 0.726 & 0.725 \\
\hline 74 & 1.831 & 5.462 & 0.858 & 0.781 & 0.603 \\
\hline 70 & & & & 0.796 & 0.597 \\
\hline 76 & 1.657 & 6.036 & 0.948 & 0.904 & 1.02 \\
\hline 66 & & & & 0.811 & 0.766 \\
\hline 95 & 1.793 & 5.576 & 0.876 & 1.18 & 1.03 \\
\hline 55 & & & & 0.632 & 0.603 \\
\hline 60 & 2.351 & 4.253 & 0.668 & 0.516 & 0.634 \\
\hline 101 & 2.123 & 4.711 & 0.740 & 0.784 & 0.800 \\
\hline 99 & & 4.074 & 0.640 & 0.855 & 1.00 \\
\hline 113 & 2.454 & 4.014 & 0.040 & 0.868 & 0.531 \\
\hline 77 & 1.248 & 8.015 & 1.26 & 1.38 & 0.691 \\
\hline 110 & 3.056 & 3.727 & 0.514 & 0.806 & - \\
\hline
\end{tabular}

* reference $\mathrm{PCB}$,

a contents $>0.2 \%$ considered as major constituents,

b systematic PCB numbering according to Ballschmiter et al. [8],

c recalculated from data published by Mullin et al. [4],

d recalculated from data published by Cooper et al. [2] similar conditions. In the following we shall show the use of the major constituents of Aroclor 1242 and Aroclor 1260.

\section{Calibration of ECD}

Figures 1 and 2 show separations of Aroclor 1242 and Aroclor 1260 , respectively, under conditions similar to those published for the separation of these formula-

Table Il Mass responses (R), mass response factors (RF) and relative mass response factors (RRF) of major ${ }^{\mathbf{a}} \mathrm{PCB}$ congeners found for ECD by GC of Aroclor 1242.

\begin{tabular}{|c|c|c|c|c|c|}
\hline $\mathbf{S N}^{\mathrm{b}}$ & ${ }_{10^{6}}^{\stackrel{\mathrm{R}}{\mathrm{R}} \text { chts pg }} \mathrm{pg}^{-1}$ & $\begin{array}{c}\text { RF } \\
\text { ng } 10^{-7} \mathrm{cnts}^{-1}\end{array}$ & RRF & $\mathrm{RRF}^{\mathrm{c}}$ & $R R F^{d}$ \\
\hline 52 & 1.452 & 6.885 & 1.77 & 3.10 & 1.32 \\
\hline 66 & & & & 2.00 & 1.61 \\
\hline 95 & 1.492 & 6.705 & 1.72 & 2.92 & 2.17 \\
\hline 84 & & & & 3.86 & 1.6 \\
\hline 89 & 1.526 & 6.554 & 1.69 & 2.31 & 0.757 \\
\hline 92 & & & & 2.41 & 1.82 \\
\hline 90 & & & & 2.12 & 2.10 \\
\hline 101 & 1.487 & 6.723 & 1.73 & 1.94 & 1.68 \\
\hline 87 & 2.944 & 3.396 & 0.874 & 1.27 & 1.06 \\
\hline 148 & 1.676 & 5.968 & 1.54 & 2.34 & 2.07 \\
\hline 110 & 2.146 & 4.661 & 1.20 & 1.99 & - \\
\hline 151 & 2.227 & 4.490 & 1.16 & 1.65 & 0.921 \\
\hline 135 & 2.047 & 4.885 & 1.26 & 1.84 & 1.43 \\
\hline 144 & 3.020 & 3.311 & 0.852 & 1.48 & 1.33 \\
\hline 118 & & & & 1.49 & 1.32 \\
\hline 149 & 1.472 & 6.795 & 1.74 & 2.26 & 1.42 \\
\hline 134 & 2.599 & 3.848 & 0.990 & 1.77 & 1.28 \\
\hline 146 & 1.177 & 8.497 & 2.19 & 1.78 & 2.30 \\
\hline 132 & 2.007 & 4.983 & 1.28 & 1.77 & 1.51 \\
\hline 153 & 1.513 & 6.608 & 1.70 & 1.88 & 0.967 \\
\hline 141 & 3.094 & 3.232 & 0.832 & 0.958 & 0.528 \\
\hline 179 & 2.295 & 4.357 & 1.12 & 1.57 & 1.37 \\
\hline 130 & 2095 & 3.339 & 0850 & 1.36 & 1.49 \\
\hline 176 & 2.975 & 年 & 0.039 & 1.22 & - \\
\hline 138 & & & & 1.57 & 1.19 \\
\hline 163 & 2.083 & 4.802 & 1.24 & 1.30 & 1.34 \\
\hline 164 & & & & 1.31 & 1.25 \\
\hline 158 & 3.040 & 3.289 & 0.846 & 1.14 & 0.947 \\
\hline 159 & & & & 1.30 & 1.32 \\
\hline 182 & 2.216 & 4.513 & 1.16 & 1.15 & 1,10 \\
\hline 187 & & & & 1.15 & 0.724 \\
\hline 128 & 2.728 & 3.666 & 0.943 & 1.09 & 1.63 \\
\hline 183 & 3.010 & 3.323 & 0.855 & 1.33 & 1.20 \\
\hline 167 & 3.201 & 3.124 & 0.839 & 1.22 & 1.09 \\
\hline 174 & 2.467 & 4.053 & 1.04 & 1.61 & 1.34 \\
\hline 177 & 2.549 & 3.923 & 1.01 & 1.28 & 0.641 \\
\hline 156 & 3.187 & 3.138 & 0.807 & 0.932 & 1.04 \\
\hline 171 & & & & 1.11 & 1.09 \\
\hline 172 & 3.172 & 3.152 & 0.811 & 1.10 & 1.57 \\
\hline 192 & & & 0.011 & 0.810 & 0.704 \\
\hline $180^{*}$ & 2.573 & 3.886 & 1.00 & 1.00 & 1.00 \\
\hline 170 & 2.779 & 3.598 & 0.926 & 1.73 & 0.862 \\
\hline 190 & 3.823 & 2.615 & 0.673 & 0.988 & 0.858 \\
\hline 196 & 3.701 & 2.702 & 0.695 & 1.05 & 1.26 \\
\hline 203 & & not & 0.08 & 0.795 & 0.829 \\
\hline
\end{tabular}

* reference $\mathrm{PCB}$,

a contents $>0.4 \%$ considered as major constituents,

b systematic PCB numbering according to Ballschmiter et al. [8],

c recalculated from data published by Mullin et al. [4],

d recalculated from data published by Cooper et al. [2] 
tions by GC-FID [7]. To identify peaks in these chromatograms, systematic PCB numbering according to Ballschmiter et al. [8] was used, as described for GCFID chromatograms [7]. The very good agreement for the corresponding chromatograms, obtained by from Aroclor 1242 and Aroclor 1260 with GC-FID [7] and GC-ECD (Figures 1 and 2), allowed straight forward correlation. Knowing the major constituent composition of Aroclor 1242 and 1260 as previously determined [7], mass responses (R), mass response factors (RF) and relative mass response factors (RRF) were calculated for the major PCB congeners found in Aroclor 1242 and 1260 . The results are in Tables I and II, respectively. For comparison, RRF values were recalculated from the data published by Mullin et al. [4] and Cooper et al. [2] and included in Tables I and II for corresponding pure congeners.

Although GC-ECD is the method of choice for trace analysis, it is obvious from Figures 1 and 2 and Tables I and II that even capillary columns give peak overlap. In such cases the determination of individual congeners is very difficult, even if the response factors of all congeners are known. Determination of partially coeluting PCB congeners is further complicated if $\mathrm{PCB}$ isomers overlap, because it is difficult to determine the response values.

Consequently, the responses determined for overlapping congeners, including isomers, by using technical PCB formulations are more realistic than mean response factors determined from single standard response factors. The composition of overlapping congeners, differing in the number of chlorine atoms, was determined by GC-MS-SIM (see below). This, however, was not considered in Tables I and II, where for all overlapping peaks only one RRF is given as determined from the detector responses and the corresponding contents in Aroclor 1242 or 1260 [7].

Comparison of corresponding measured and published RRF values in Tables I and II shows reasonable agreement in many cases. However, in both Tables I and II relatively large differences between corresponding RRF's occur when peaks overlap. In these instances it is not feasible to tabulate ECD, RRF data for individual PCBs.

\section{Calibration of MS-TIC}

Figures 3 and 4 show chromatograms for Aroclor 1242 and 1260 , respectively, reconstructed by computer from experimental data. The chromatographic conditions were again similar to those published for the separation of these formulations [7]. Comparing the chromatograms obtained by separating Aroclor 1242 and 1260 with both GC-FID [7] and GC-MS-TIC (Figures 3 and 4), very good agreement of retention times and chromatographic patterns can be obtained. Since in all cases equal amounts of PCBs were analyzed, comparison of the signal-to-noise ratios shows that the sensitivity of both the FID and MS-TIC for corresponding PCBs is practically the same.

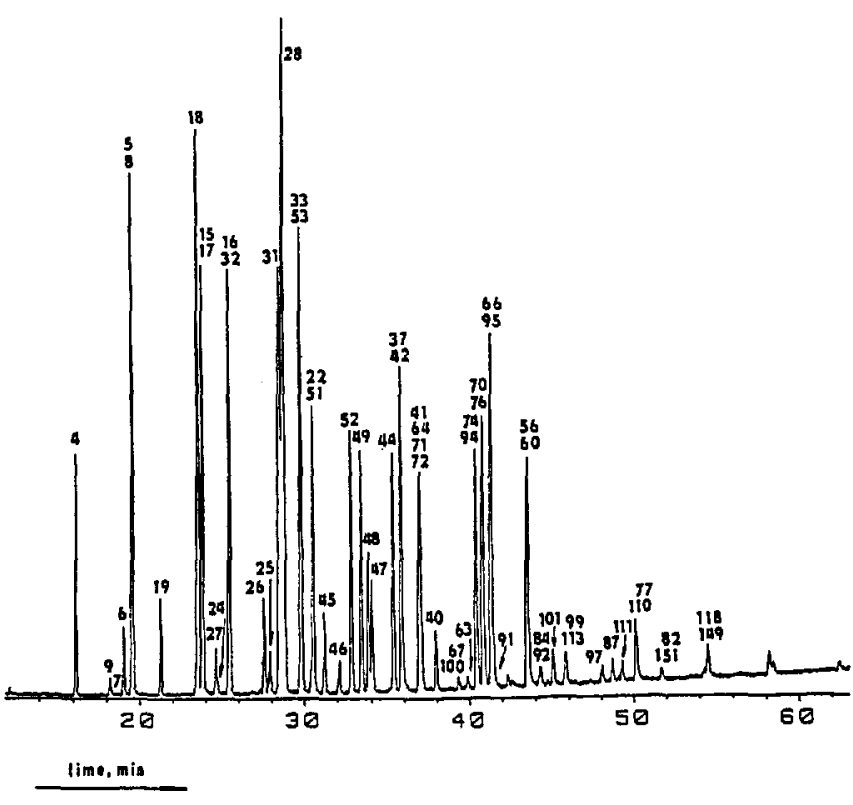

Figure 3

Computer reconstructed chromatogram of $100 \mathrm{ng}$ Aroclor 1242 by GC-MS-TIC. Details, see Experimental.

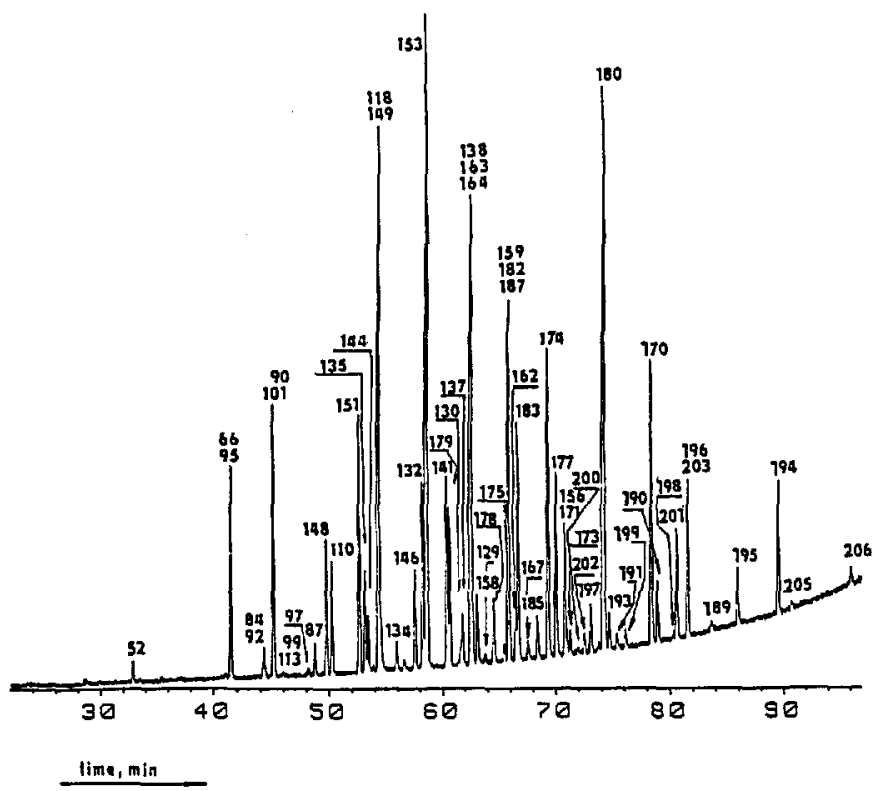

Figure 4

Computer reconstructed chromatogram of 100ng Aroclor 1260 by GC-MS-TIC. Details, see Experimental.

The mass responses (R), mass response factors (RF) and relative mass response factors (RRF) of the major congeners, found by MS-TIC detection by analysis of Aroclor 1242 and 1260, are in Tables III and IV, respectively. From the data in Tables I to IV it follows that, for corresponding PCBs, the MS-TIC technique gives higher responses than ECD. In spite of this, MSTIC is much less sensitive in practice, because its noise level is about $10^{3}$ times higher than that for ECD. From Tables III and IV it further follows that the responses do not differ substantially $\left(\overline{\mathrm{R}}=1.186 \times 10^{7}\right.$ counts, standard deviation $\sigma=0.182 \times 10^{7}$ Table III, and 
Table 11 Mass responses (R), mass response factors (RF) and relative mass response factors (RRF) of major ${ }^{a}$ PCB congeners found for MS-TIC by GC of Aroclor 1242.

\begin{tabular}{|c|c|c|c|}
\hline $\mathrm{SN}^{\mathrm{b}}$ & $\mathrm{R}, 10^{7} \mathrm{cnts} \mathrm{ng}^{-1}$ & RF, ng $10^{-3} \mathrm{cnts}^{-1}$ & RRF \\
\hline 4 & 1.011 & 9.895 & 1.22 \\
\hline 6 & 1.178 & 8.486 & 1.05 \\
\hline $\begin{array}{l}5 \\
8\end{array}$ & 1.005 & 9.946 & 1.23 \\
\hline 19 & 1.407 & 7.109 & 0.879 \\
\hline 18 & 0.9993 & 10.00 & 1.24 \\
\hline 15 & & & \\
\hline 17 & 1.033 & 9.679 & 1.20 \\
\hline 27 & 1.714 & 5.835 & 0.722 \\
\hline 16 & 1.062 & 9.414 & 1.16 \\
\hline 32 & 1.002 & 8730 & 108 \\
\hline $\begin{array}{l}26 \\
25\end{array}$ & $\begin{array}{l}1.146 \\
1.253\end{array}$ & $\begin{array}{l}8.130 \\
7.983\end{array}$ & $\begin{array}{l}1.08 \\
0.988\end{array}$ \\
\hline 31 & 1.092 & 9.161 & 1.13 \\
\hline 28 & 1.102 & 9.074 & 1.12 \\
\hline 33 & & & \\
\hline 53 & 1.101 & 9.086 & 1.12 \\
\hline 22 & 1327 & 0004 & 10 \\
\hline 51 & 1.123 & 8.904 & 1.10 \\
\hline 45 & 1.445 & 6.921 & 0.856 \\
\hline 46 & 1.826 & 5.476 & 0.677 \\
\hline $\begin{array}{l}52 \\
69\end{array}$ & 1.185 & 8.439 & 1.04 \\
\hline 49 & 1.199 & 8.342 & 1.03 \\
\hline 48 & 1.082 & 9.243 & 1.14 \\
\hline 47 & 1.157 & 8.641 & 1.07 \\
\hline $44^{*}$ & 1.237 & 8.084 & 1.00 \\
\hline $\begin{array}{l}37 \\
42\end{array}$ & 1.008 & 9.921 & 1.23 \\
\hline 41 & & & \\
\hline $\begin{array}{l}64 \\
71\end{array}$ & 1.180 & 8.478 & 1.05 \\
\hline 72 & & & \\
\hline 40 & 1.144 & 8.743 & 1.08 \\
\hline 74 & 1.181 & 8.466 & 1.05 \\
\hline 70 & 1.156 & 8.648 & 1.07 \\
\hline $\begin{array}{l}76 \\
66\end{array}$ & & & \\
\hline $\begin{array}{l}00 \\
95\end{array}$ & 1.138 & 8.791 & 1.09 \\
\hline 50 & & & \\
\hline 60 & 1.132 & 8.830 & 1.09 \\
\hline 101 & 1.057 & 9.457 & 1.17 \\
\hline 99 & 1292 & 7747 & 0958 \\
\hline 113 & & 7.742 & 0.900 \\
\hline 77 & 1.199 & 8.337 & 1.03 \\
\hline 110 & 1.105 & 9.047 & 1.12 \\
\hline
\end{tabular}

$\overline{\mathbf{R}}=1.186, \sigma=0.182$

$\overline{\mathrm{RRF}}=1.094$

* reference $\mathrm{PCB}$,

contents $>0.2 \%$ considered as major constituents,

b systematic PCB numbering according to Ballschmiter et al. [8]

$R=1.074 \times 10^{7}$, standard deviation $\sigma=0.109 \times 10^{7}$ Table IV) which allows, without calibrating the responses, to analyze the PCB samples semiquantitatively in GC-MS-TIC mode in weight percent.

Figures 5 and 6 show the separation of Aroclor 1242 and 1260 , respectively, reconstructed by computer from experimental data obtained by monitoring the most abundant $\mathrm{M}^{+}$ions (see Figures 7-10). Comparison of Figures 3 and 4 with Figures 5 and 6 shows a very
Table IV Mass responses (R), mass response factors (RF) and relative mass response factors (RRF) of major ${ }^{a} \mathrm{PCB}$ congeners found for MS-TIC by GC of Aroclor 1260.

\begin{tabular}{|c|c|c|c|}
\hline$S N^{b}$ & $\mathrm{R}, 10^{6} \mathrm{cnts} \mathrm{pg}^{-1}$ & RF, ng $10^{-7} \mathrm{cnts}^{-1}$ & RRF \\
\hline 52 & 1.224 & 8.172 & 0.828 \\
\hline 66 & & & \\
\hline $\begin{array}{l}95 \\
84\end{array}$ & 1.223 & 8.177 & 0.828 \\
\hline 89 & 1.038 & 9.629 & 0.975 \\
\hline $\begin{array}{l}92 \\
90\end{array}$ & & & \\
\hline 101 & & & \\
\hline 87 & 1.238 & 8.077 & 0.817 \\
\hline 148 & 1.108 & 9.027 & 0.914 \\
\hline 110 & 1.150 & 8.693 & 0.881 \\
\hline 151 & 1.234 & 8.102 & 0.821 \\
\hline 135 & 0.9806 & 10.20 & 1.03 \\
\hline 144 & 0.8701 & 11.49 & 1.16 \\
\hline 118 & & & \\
\hline 149 & 1.085 & 9.219 & 0.934 \\
\hline 134 & 0.9123 & 10.96 & 1.11 \\
\hline 146 & 1.129 & 8.854 & 0.897 \\
\hline 132 & 1.202 & 8.317 & 0.842 \\
\hline 153 & 1.121 & 8.918 & 0.903 \\
\hline 141 & 1.1846 & 8.442 & 0.855 \\
\hline 179 & 0.9715 & 10.29 & 1.04 \\
\hline 130 & & & \\
\hline 176 & 0.9650 & 10.36 & 1.05 \\
\hline 138 & & & \\
\hline 163 & 1.127 & 8.873 & 0.899 \\
\hline 164 & & & \\
\hline 158 & 0.8875 & 11.27 & 1.14 \\
\hline 159 & & & \\
\hline 182 & 1.074 & 9.311 & 0.943 \\
\hline 187 & & & \\
\hline 128 & 0.9878 & 10.12 & 1.02 \\
\hline 183 & 1.052 & 9.502 & 0.962 \\
\hline 167 & 1.254 & 7.974 & 0.808 \\
\hline 174 & 1.028 & 9.728 & 0.985 \\
\hline 177 & 1.073 & 9.319 & 0.944 \\
\hline 156 & & & \\
\hline 171 & 1.164 & 8.591 & 0.870 \\
\hline 172 & & & \\
\hline 192 & 0.9689 & 10.321 & 1.04 \\
\hline $180^{*}$ & 1.013 & 9.872 & 1.00 \\
\hline 170 & 0.9801 & 10.20 & 1.03 \\
\hline 190 & 0.9936 & 10.06 & 1.02 \\
\hline 196 & & & \\
\hline 203 & 0.9908 & 10.09 & 1.02 \\
\hline 194 & 1.006 & 9.940 & 1.01 \\
\hline \multicolumn{3}{|c|}{$\mathrm{R}=1.074, \sigma=0.109$} & $=0.955$ \\
\hline
\end{tabular}

similar chromatographic pattern but the signal-to-noise ratio is much higher in Figures 5 and 6 since the sensitivity of the MS-SIM technique is much higher than MS-TIC for PCBs.

\section{Calibration of MS-SIM}

From data obtained from Aroclor 1242 and 1260 by GC-MS-SIM, the computer constructed single-ion masschromatograms (fragmentograms) shown in Figures 


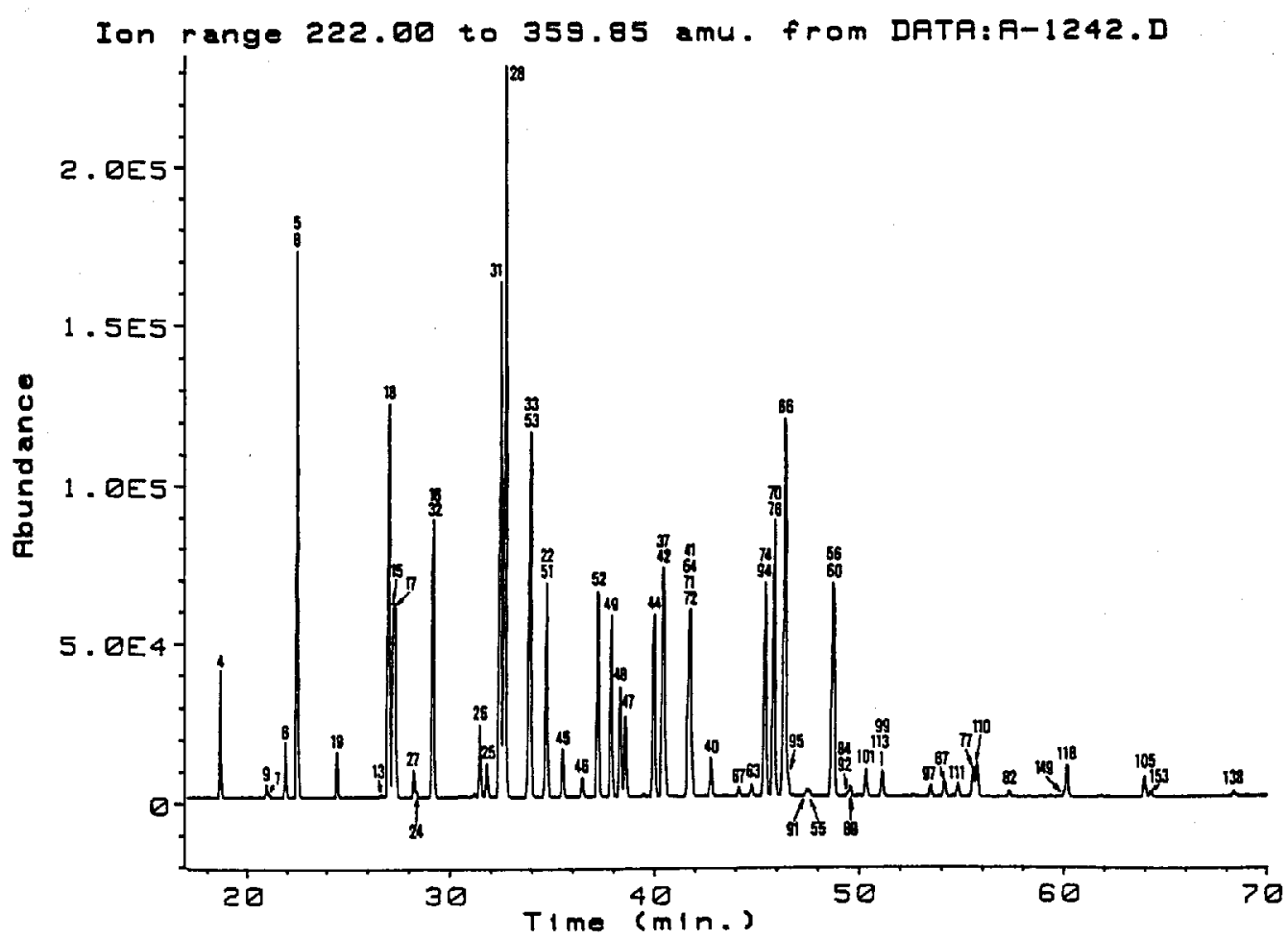

Figure 5

Computer reconstructed chromatogram (summed MS-SIM responses versus time) of 50ng Aroclor 1242 by GC-MS-SIM. Details, see Experimental.

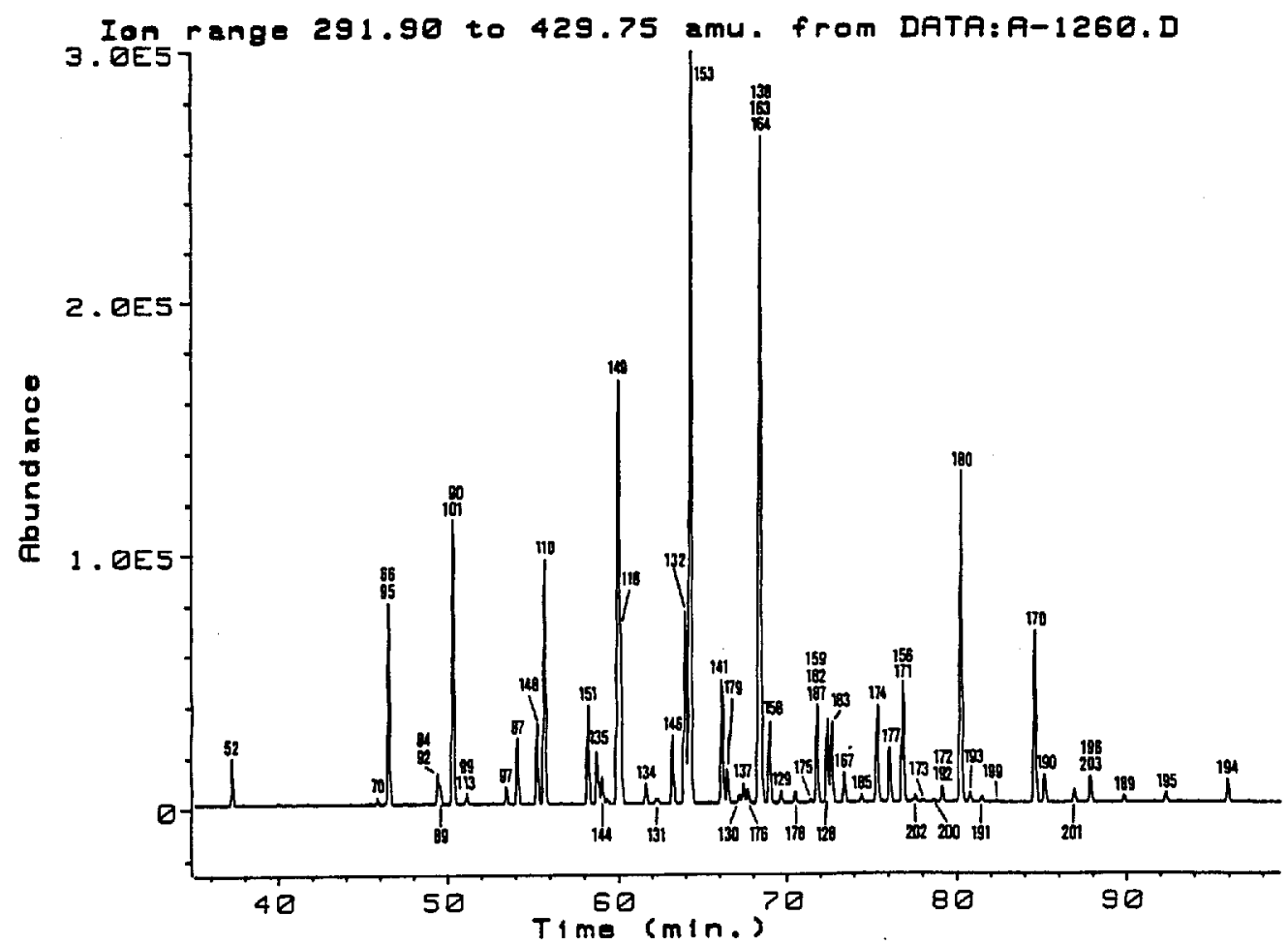

Figure 6

Computer reconstructed chromatogram (summed MS-SIM responses versus time) of 50ng Aroclor 1260 by GC/SIM. Details, see Experimental.

7-10. In the electron impact mass spectra, the most abundant ions correspond to even masses in the molecular ion clusters $\left(\mathrm{M}^{+}\right)$, followed by $\mathrm{M}^{+}-\mathrm{Cl}_{2}$ fragments at $(\mathrm{M}-70)^{+}$. Far less abundant is the (M$35)^{+}$cluster at odd masses. It is obvious in Figures 4 and 5 that the co-eluting $\mathrm{PCB}$ isomers cannot be resolved. Co-eluting congeners, containing fewer chlorines than the monitored congener, do not interfere with the measured $\mathrm{M}^{+}$ions produced by latter. Fragment ions produced by co-eluting congeners containing 

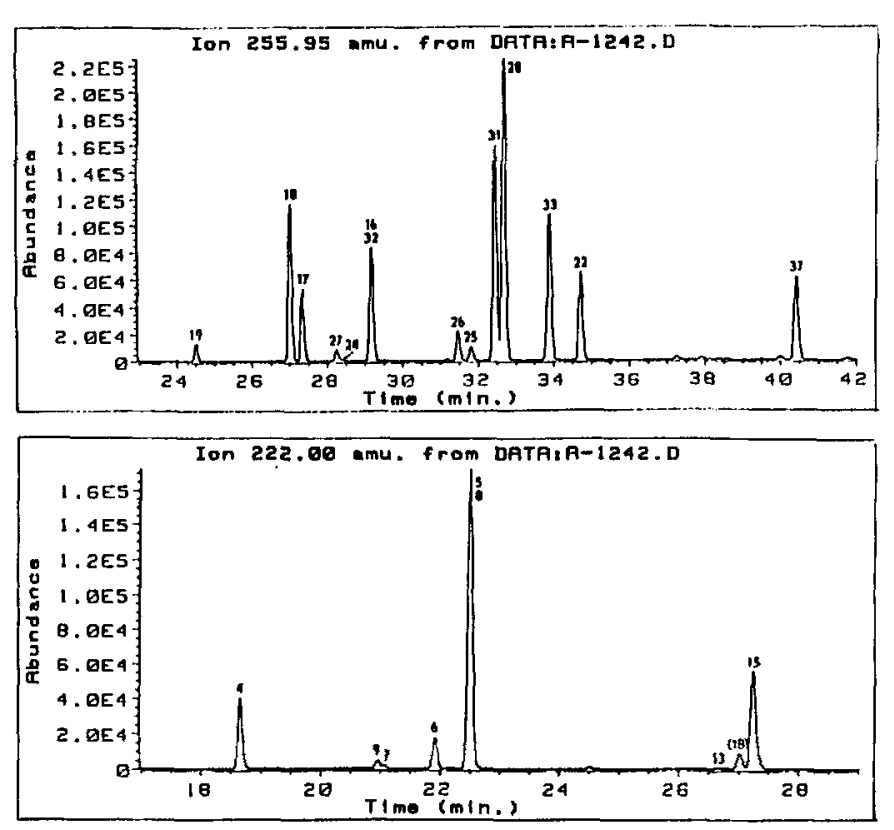

Figure 7

Partial fragmentograms $(\mathrm{m} / \mathrm{z} 222,256)$ of $50 \mathrm{ng}$ Aroclor 1242 by $\mathrm{GC}$. MS-SIM. Details, see text.
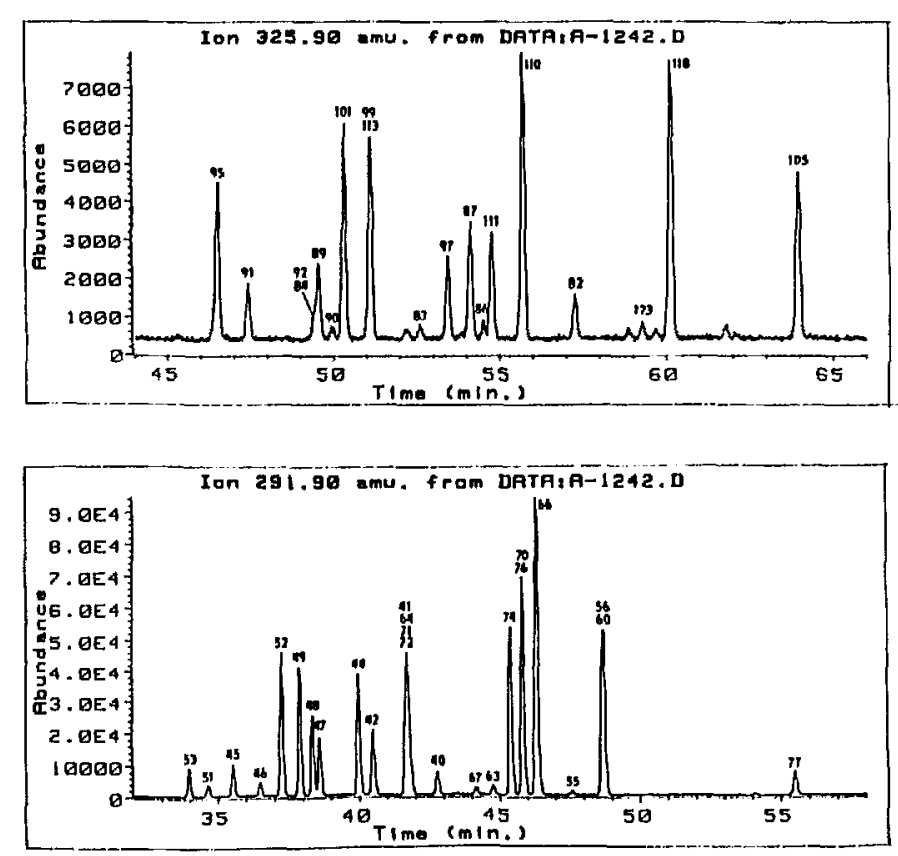

Figure 8

Partial fragmentograms (m/z 292, 326) of 50ng Aroclor 1242 by GCMS-SIM. Details, see text.

more chlorines than the test congener, however, can interfere. Therefore, characterization of congeners by their response in an $\mathrm{M}^{+}$ion cluster was verified by the absence of pertinent ions of higher mass.

As already mentioned, PCBs undergo a characteristic loss of two chlorines to produce a $(\mathrm{M}-70)^{+}$cluster that partially overlaps the $\mathrm{M}^{+}$cluster produced by a congener containing two chlorines less. These clusters contain ions that have the same masses but differ in relative abundance, which can be detected in full mass spectra but not in fragmentograms. Therefore, to verify
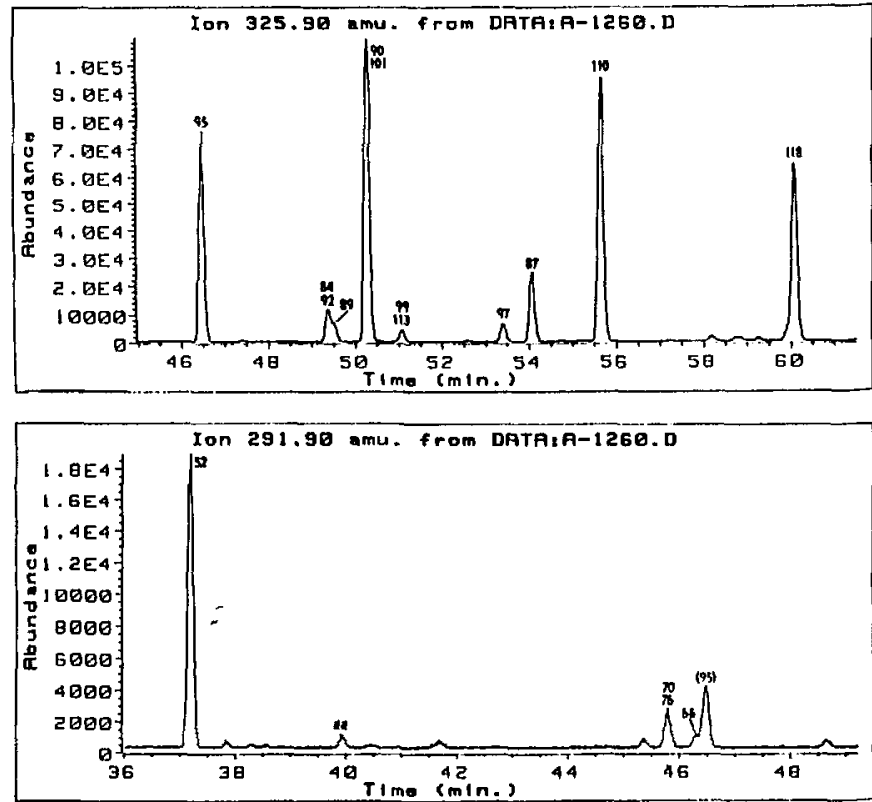

Figure 9

Partial fragmentograms ( $\mathrm{m} / \mathrm{z} 292,326)$ of $50 \mathrm{ng}$ Aroclor 1260 by GCMS-SIM. Details, see text.
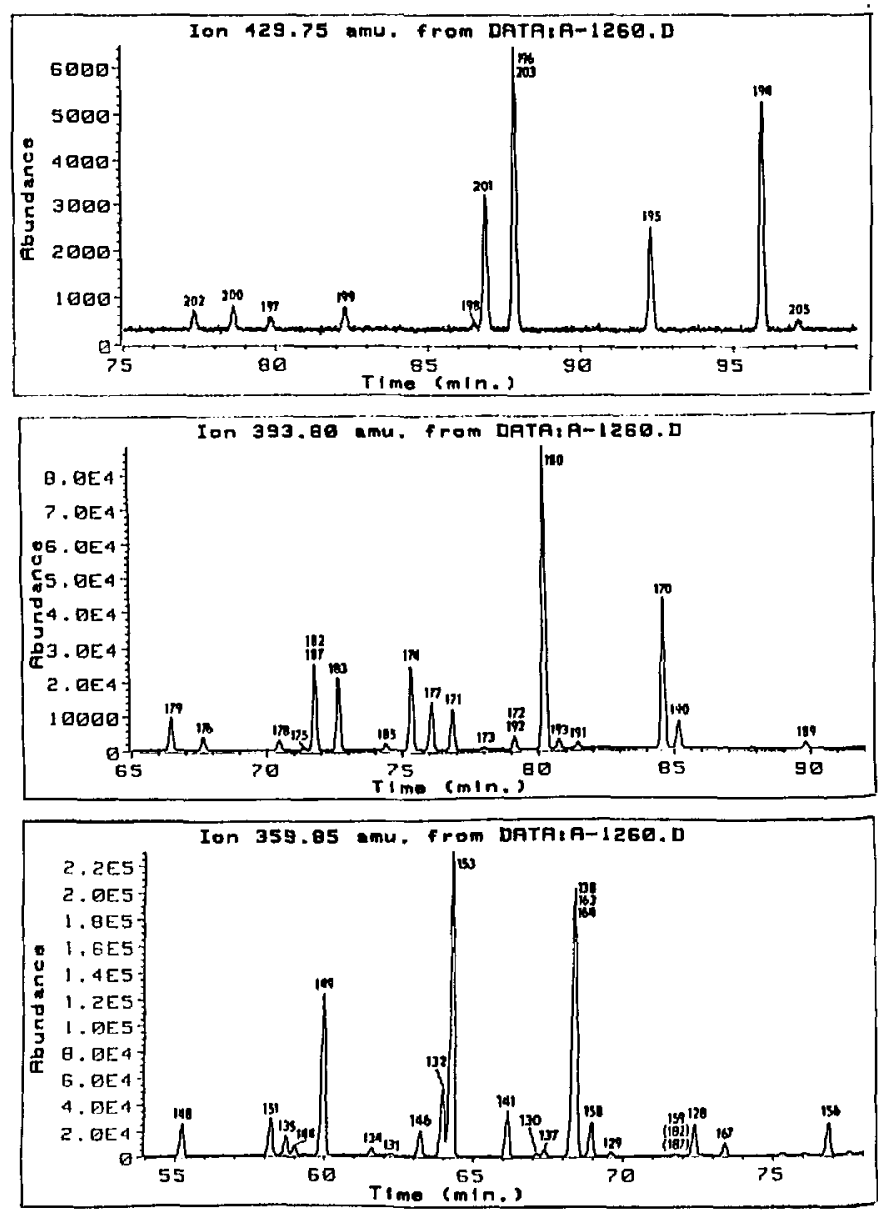

Figure 10

Partial fragmentograms $(\mathrm{m} / \mathrm{z} 360,394,430)$ of 50ng Aroclor 1260 by GC-MS-SIM. Details, see text.

a tentative assignment of the level of chlorination, the observed relative abundance of isotope clusters had to be sufficiently similar to expected relative abundances. 
Table $\mathrm{V}$ Mass responses (R), mass response factors (RF) and relative mass response factors (RRF) of the major PCB congeners found for MS. SIM by GC of Aroclor 1242 and 1260.

\begin{tabular}{|c|c|c|c|c|c|c|c|}
\hline$S N^{b}$ & $\mathrm{R}, 10^{6} \mathrm{cnts} \mathrm{ng^{-1 }}$ & $\mathrm{RF}, \mathrm{ng} 10^{-7} \mathrm{cnts}^{-1}$ & RRF & $\mathrm{SN}^{\mathrm{b}}$ & $\mathrm{R}, 10^{6}$ cnts ng ${ }^{-1}$ & $\mathrm{RF}, \mathrm{ng} 10^{-7} \mathrm{cnts}^{-1}$ & RRF \\
\hline \multicolumn{4}{|c|}{ Dichlorobiphenyl isomers ( $\mathrm{m} / \mathrm{z} 222$ ) } & & & & \\
\hline 4 & 1.706 & 5.860 & 1.62 & \multicolumn{4}{|c|}{ Hexachlorobiphenyl isomers $(\mathrm{m} / \mathrm{z}, 360)$} \\
\hline 7,9 & 3.106 & 3.220 & 0.888 & 148 & 3.470 & 2.882 & 0.770 \\
\hline 6 & 3.850 & 2.598 & 0.716 & 151 & 2.599 & 3.847 & 1.03 \\
\hline $5,8^{*}$ & 2.758 & 3.626 & 1.00 & 135 & 2.390 & 4.183 & 1.12 \\
\hline 15 & 2.582 & 3.872 & 1.07 & 144 & 2.585 & 3.869 & 1.03 \\
\hline \multicolumn{4}{|c|}{ Trichlorobiphenyl isomers $(\mathrm{m} / \mathrm{z} 256)$} & 149 & 2.354 & 4.248 & 1.13 \\
\hline 19 & 2.066 & 4.840 & 1.22 & 134 & 2.423 & 4.127 & 1.10 \\
\hline 18 & 1.916 & 5.219 & 1.31 & 131 & 3.099 & 3.226 & 0.968 \\
\hline 17 & 1.959 & 5.105 & 1.28 & 146 & 2.758 & 3.626 & 1.01 \\
\hline 27 & 3.103 & 3.222 & 0.811 & 132 & 2.725 & 3.669 & 0.980 \\
\hline 16,32 & 2.190 & 4.566 & 1.15 & $153^{*}$ & 2.671 & 3.744 & 1.00 \\
\hline 26 & 3.103 & 3.222 & 0.811 & 141 & 2.506 & 3.991 & 1.07 \\
\hline 25 & 3.014 & 3.318 & 0.835 & 130 & 2.889 & 3.468 & 0.926 \\
\hline 31 & 2.951 & 3.389 & 0.853 & $138,163,164$ & 2.707 & 3.694 & 0.98 \\
\hline $28^{*}$ & 2.518 & 3.971 & 1.00 & 158 & 3.172 & 3.153 & 0.842 \\
\hline 33 & 2.706 & 3.695 & 0.930 & 129 & 2.689 & 3.719 & 0.993 \\
\hline 22 & 2.795 & 3.578 & 0.901 & 128 & 3.758 & 2.661 & 0.711 \\
\hline \multicolumn{4}{|c|}{ Tetrachlorobiphenyl isomers (m/z 292) } & 167 & 3.909 & 2.558 & 0.683 \\
\hline 53 & 2.732 & 3.666 & 0.811 & 156 & 3.452 & 2.897 & 0.774 \\
\hline 51 & 2.781 & 3.595 & 0.797 & \multicolumn{4}{|c|}{ Heptachlorobiphenyl isomers $(\mathrm{m} / \mathrm{z} 394)$} \\
\hline 45 & 2.239 & 4.466 & 0.989 & 179 & 2.038 & 4.908 & 0.887 \\
\hline 46 & 2.062 & 4.851 & 1.07 & 176 & 1.732 & 5.775 & 1.04 \\
\hline 52 & 2.400 & 4.167 & 0.923 & 178 & 2.106 & 4.748 & 0.858 \\
\hline 49 & 2.578 & 3.880 & 0.860 & 175 & 1.631 & 6.131 & 1.11 \\
\hline 48 & 2.885 & 3.466 & 0.768 & 182,187 & 1.858 & 5.383 & 0.973 \\
\hline 47 & 2.453 & 4.077 & 0.903 & 183 & 2.056 & 4.865 & 0.880 \\
\hline $44^{*}$ & 2.215 & 4.514 & 1.00 & 185 & 2.117 & 4.724 & 0.854 \\
\hline 42 & 3.427 & 2.918 & 0.646 & 174 & 1.793 & 5.570 & 1.01 \\
\hline $41,64,71,72$ & 3.197 & 3.128 & 0.693 & 177 & 1.699 & 5.885 & 1.06 \\
\hline 40 & 2.131 & 4.692 & 1.04 & 171 & 2.020 & 4.951 & 0.895 \\
\hline 70,76 & 3.509 & 2.850 & 0.631 & $172,192,147$ & 1.807 & 5.533 & 1.00 \\
\hline 66 & 3.326 & 3.006 & 0.666 & $180^{*}$ & 1.807 & 5.533 & 1.00 \\
\hline 56,60 & 4.034 & 2.479 & 0.549 & 193 & 2.002 & 4.996 & 0.903 \\
\hline 77 & 3.657 & 2.734 & 0.606 & 191 & 2.207 & 4.531 & 0.819 \\
\hline \multicolumn{4}{|c|}{ Pentachlorobiphenyl isomers $(\mathrm{m} / \mathrm{z} 326)$} & 170 & 1.753 & 5.704 & 1.03 \\
\hline $95^{*}$ & 2.855 & 3.503 & 1.00 & 190 & 2.120 & 4.716 & 0.853 \\
\hline 84,92 & 3.748 & 2.668 & 0.762 & \multicolumn{4}{|c|}{ Octachlorobiphenyl isomers $(\mathrm{m} / \mathrm{z} 430)$} \\
\hline 90,101 & 3.017 & 3.314 & 0.946 & 199 & 2.020 & 4.951 & 0.772 \\
\hline 99,113 & 3.974 & 2.516 & 0.718 & 198 & 1.397 & 7.159 & 1.12 \\
\hline 97 & 3.775 & 2.663 & 0.760 & 201 & 1.559 & 6.415 & 1.00 \\
\hline 87 & 2.264 & 4.416 & 1.26 & 196,203 & 1.670 & 5.987 & 0.933 \\
\hline 110 & 3.928 & 2.546 & 0.727 & 195 & 1.469 & 6.808 & 1.06 \\
\hline 82 & 2.833 & 3.530 & 1.01 & 194 & 1.613 & 6.200 & 0.966 \\
\hline 124 & 2.851 & 3.507 & 1.00 & 205 & 1.192 & 8.392 & 1.31 \\
\hline 118 & 2.560 & 3.907 & 1.11 & & & & \\
\hline
\end{tabular}

* reference $\mathrm{PCB}$

In Figures 7-10, further interference is caused by a (M$\mathrm{Cl})^{+}$fragment ion-cluster containing a single naturally occurring ${ }^{13} \mathrm{C}$ isotope. That cluster contains ions with the same mass and relative abundance as the ${ }^{12} \mathrm{C}$ isotope $\mathrm{M}^{+}$cluster of isomers containing one chlorine less. This ${ }^{13} \mathrm{C}$ contribution is not constant (varies between $5-15 \%$ of corresponding $\mathrm{M}^{+}$ions) and cannot be filtered. It is, inter alia, one of the main sources of error, arising from overlapping PCB congeners with different number of chlorines, which influences the precision of the RRF measurements.

Table $\mathrm{V}$ shows mass responses, mass response factors and relative mass response factors of the major PCB congeners found by the MS-SIM technique, by GC of
Aroclor 1242 and 1260 . From the data in Table V it follows that the response of the MS-SIM technique differs to a much greater extent than those in Tables III and IV for MS-TIC techniques. Consequently, RRF values in each isomer group also differ substantially.

Table VI shows mean responses their standard deviations $\left(\sigma_{R}\right)$ and maximum ratio of response $\left(R_{\max } /\right.$ $R_{\text {min }}$ ), calculated for each $P C B$ isomer group from the results in Table $V$. For comparison, $R_{\max } / R_{\min }$ data published by Gebhart et al. [6] are included. Relatively good agreement is seen from comparison of measured and published values, except for hexa and heptachlorobiphenyl isomers. From Tables V and VI it is obvious that the MS-SIM technique must be calibrated 
Table VI Mean responses $(\bar{R})$, standard deviations $\left(\sigma_{\bar{R}}\right)$ and maximum response ratios $\left(R_{\min } / R_{\min }\right)$ calculated for each PCB isomer group from the results in Table $V$.

\begin{tabular}{|lccccc|}
\hline \multirow{2}{*}{ PCB isomers } & $\bar{R}$ & \multicolumn{2}{c|}{$\sigma_{\mathrm{R}}$} & \multicolumn{2}{c|}{$\mathrm{R}_{\max } / \mathrm{R}_{\min }$} \\
& $10^{6}$ cnts ng $^{-1}$ & $10^{6}$ cnts ng $^{-1}$ & Exp $^{\text {Publ }^{\mathrm{a}}}$ \\
\hline Dichlorobiphenyls & 2.800 & 0.781 & 2.26 & 1.8 \\
Trichlorobiphenyls & 2.484 & 0.657 & 1.62 & 2.1 \\
Tetrachlorobiphenyls & 2.852 & 0.607 & 1.95 & 1.8 \\
Pentachlorobiphenyls & 3.178 & 0.617 & 1.75 & 2.1 \\
Hexachlorobiphenyls & 2.898 & 0.474 & 1.65 & 3.1 \\
Heptachlorobiphenyls & 1.922 & 0.180 & 1.36 & 2.9 \\
Octachlorobiphenyls & 1.560 & 0.257 & 1.70 & 1.6 \\
\hline
\end{tabular}

${ }^{a}$ results published by Gebhard et al. [6], relative to chrysene-d ${ }_{12}$.

Table VII Comparison of minimum counts, amounts and contents corresponding to signal-to-noise ratio of $3: 1$ as found by $\mathrm{GC}$ of 2,2 , 3,5'-tetrachlorobiphenyl (peak No. 44).

\begin{tabular}{|lccc|}
\hline Detector & Counts & Amount, pg & Content, ppb \\
\hline FID & $1 \cdot 10^{12}$ & 100 & 100 \\
MS-TIC & $4 \cdot 10^{6}$ & 400 & 400 \\
MS-SIM & $3 \cdot 10^{4}$ & 5 & 5 \\
ECD & $6 \cdot 10^{3}$ & 0.5 & 0.5 \\
\hline
\end{tabular}

prior to its use for PCB trace analysis. The use of mean response factors for each PCB isomers group, as proposed by Gebhart et al. [6], is therefore not applicable as the error can easily exceed fifty percent.

\section{Comparison of FID, ECD, MS-TIC and MS-SIM}

Table VII compares minimum counts, amounts and contents corresponding to a signal-to-noise ratio of $3: 1$ as found by analysis of $2,2^{\prime}, 3,5^{\prime}$-tetrachlorobiphenyl (peak No. 44) using on-column injection. From Table VII it follows that ECD is the most sensitive detector for PCBs. MS-SIM detection is also applicable although its sensitivity is about ten times smaller than that of the ECD. Negative-ion (methylene chloride and/or oxygen) chemical-ionization, mass spectrometry might be used to advantage for trace PCB analysis because its sensitivity approaches that of ECD [9]. Calibration of this technique is the subject of further investigation. Table VII also shows that FID and MSTIC are not sufficiently sensitive for trace analysis. The validity of the last is, however, relative as the data given in Table VII were calculated from non-smoothed signals. It is likely that the use of suitable smoothing can improve the signal-to-noise ratio to such an extent that even FID and MS-TIC can be exploited. This subject is currently being studied at the Analytical Chemistry Department, CHF STU in Bratislava and will be published separately.

\section{Acknowledgement}

This work was supported by a grant No. 1/990927/92 of the Slovak Ministry of Education.

\section{References}

[1] F. I. Onuska, K. A. Terry, HRC \& CC 9, 671 (1986).

[2] S. D. Cooper, M. A. Moseley, E. D. Pellizzari, Anal. Chem. 57, 2469 (1985).

[3] J. C. Duinker, M. T. J. Hillebrand, Environm. Sci. Technol. 17, 449 (1983).

[4] M. D. Mullin, C. M. Pochini, S. McCrindle, M. Romes, S. H. Safe, L. M. Safe, Environm. Sci. Technol. 18, 468 (1984).

[5] National Research Council of Canada, Institute for Marine Biosciences, Marine Analytical Chemistry Standards Program, Halifax Nova Scotia, Canada B3H3Z1, January 1985. Documentation Revised: January 1991.

[6] J. E. Gebhart, T. L. Hayes, A. L. Alford-Stevens, W. L. Budde, Anal. Chem. 57, 2458 (1985).

[7] J. Krupčik, A. Kočan, J. Petrik, P. A. Leclercq, K. H. Ballschmiter, Chromatographia 33, 514 (1992).

[8] K. Ballschmiter, W. Schafer, H. Buchert, Z. Anal. Chem. 326, 253 (1987).

[9] R. C. Dougherty, Anal. Chem. 53, 625A (1981).

Received: Nov 6, 1992 Revised manuscript received: Dec 23, 1992 Accepted: Jan 6, 1993 